\title{
Karakteristik Solusi Dekomposisi QR dalam Aljabar Max-Plus Tersimetri
}

\author{
Zakaria Bani Ikhtiyar $^{1 *}$, Saminanto ${ }^{2}$, Budi Cahyono ${ }^{3}$ \\ 1,2,3 UIN Walisongo Semarang \\ * zakaria.bani45@gmail.com
}

\begin{abstract}
ABSTRAK
Kajian aljabar max-plus tersimetri hadir dari kondisi bahwa setiap elemen pada $\mathbb{R}_{\max }$ tidak memiliki invers terhadap operasi max. Aljabar max-plus tersimetri dibentuk dari pasangan berurutan elemenelemen di $\mathbb{R}_{\max }$. Pembentukan aljabar max-plus tersimetri ini memunculkan kelas positif, kelas negatif, kelas nol, dan kelas himpunan baru, yakni kelas balance. Penelitian ini berfokus pada pencarian karakteristik solusi dekomposisi QR dalam aljabar max-plus tersimetri dengan beberapa entri matriks awal yang akan didekomposisi merupakan anggota kelas balance. Dekomposisi QR merupakan salah satu dekomposisi matriks, yaitu dekomposisi suatu matriks persegi panjang $A$ berukuran $\mathrm{m} \times \mathrm{n}$ menjadi perkalian matriks ortogonal $Q$ berukuran $\mathrm{m} \times \mathrm{m}$ dengan matriks segitiga atas $R$ berukuran $\mathrm{m} \times \mathrm{n}$. Secara umum, dekomposisi ini dapat digunakan dalam aljabar konvensional. Penelitian ini menjelaskan dekomposisi QR jika dipunyai matriks dengan entri-entri elemen balance di aljabar max-plus tersimetri.
\end{abstract}

Kata kunci: dekomposisi QR, aljabar max-plus, aljabar max-plus tersimetri, dekomposisi QR dalam aljabar max-plus tersimetri.

\section{ABSTRACT}

The symmetry max-plus algebra study comes from the condition that each element in $\mathbb{R}$ max has no inverse of max operation. The symmetry max-plus algebra is formed from ordered pairs of elements in $\mathbb{R}_{\max }$. This will bring out positive classes, negative classes, zero classes, and new set classes, namely the balance class. This study focuses on finding the characteristics of $Q R$ decomposition solutions in symmetrical max-plus algebra with some initial matrix that its entries are element of the balance class. $Q R$ decomposition is one of the matrix decompositions, namely the decomposition of a rectangular matrix $A$ with order $m \times n$ to be the multiplication of the orthogonal matrix $Q$ with order $m \times m$ with the upper triangle matrix $R$ with order $m \times n$. In general, this decomposition can be used in conventional algebra. This study explains $Q R$ decomposition if it has a matrix with symmetrical balance element entries in max-plus algebra.

Keywords: $Q R$ decomposition, max-plus algebra, symmetry max-plus algebra, $Q R$ decomposition in symmetry max-plus algebra. 


\section{PENDAHULUAN}

Dekomposisi QR sesuai dengan (Ruminta, 2014) adalah dekomposisi matriks $\boldsymbol{m} \times \boldsymbol{n}$ menjadi perkalian matriks ortogonal berukuran $\boldsymbol{m} \times \boldsymbol{m}$ dengan matriks segitiga atas berukuran $\boldsymbol{m} \times \boldsymbol{n}$. Misal dimiliki matriks $\boldsymbol{A}$ berukuran $\boldsymbol{m} \times \boldsymbol{n}$, maka dapat didekomposisi menjadi matriks $\boldsymbol{Q}$ berukuran $\boldsymbol{m} \times \boldsymbol{m}$ dan matriks $\boldsymbol{R}$ berukuran $\boldsymbol{m} \times \boldsymbol{n}$.

$$
\boldsymbol{A}=\boldsymbol{Q} \times \boldsymbol{R}
$$

Dekomposisi QR dapat dilakukan dalam himpunan bilangan real, atau dalam aljabar konvensional, hal ini dapat dilihat dalam (Ruminta, 2014), (Anton, 1987), atau (Golub \& Loan, 1996). Bart De Schutter dan Bart De Moor dalam (Schutter \& Moor, 2002) telah menjelaskan bahwa dekomposisi QR dapat dilakukan dalam aljabar max-plus. Dalam karyanya (Schutter \& Moor, 2002) tersebut, Bart De Schutter dan Bart De Moor menjelaskan bahwa untuk melakukan dekomposisi QR dalam aljabar max-plus perlu perluasan struktur baru dari struktur ajabar maxplus menjadi aljabar max-plus tersimetri. Penjelasan tentang perluasan ini diambil dari (Bacelli, 2001). Pembentukan aljabar max-plus tersimetri ini diawali dari struktur aljabar max plus dengan bentuk himpunan $\mathbb{R}_{\text {max }}=\mathbb{R} \cup\{-\infty\}$ dilengkapi dengan operasi $\oplus$ dan $\otimes$ yang didefinisikan sebagai:

$$
\begin{gathered}
a \oplus b=\max (a, b) \\
a \otimes b=a+b \\
\forall a, b \in \mathbb{R}_{\text {max }}
\end{gathered}
$$

dengan elemen nolnya adalah $-\infty$ dan elemen satuannya $\mathbf{0}$.

Pada operasi $\bigoplus$ tidak dimiliki elemen invers untuk setiap $\boldsymbol{x} \in \mathbb{R}_{\max }$. Hal ini dapat dilihat dalam persamaan berikut:

$$
x \oplus a=-\infty
$$

pada persamaan (4) tidak dapat ditemukan nilai $\boldsymbol{a}$ yang dapat memenuhi persamaan, kecuali $\boldsymbol{x}=\boldsymbol{a}=-\infty$. Hal ini mendasari pembentukan aljabar max-plus tersimetri. Dalam pembentukan aljabar max-plus tersimetri diperkenalkan struktur baru yang disebut pasangan aljabar yaitu struktur aljabar dengan himpunan $\mathbb{P}=\left\{\left(\boldsymbol{x}_{\mathbf{1}}, \boldsymbol{x}_{\mathbf{2}}\right) \mid \boldsymbol{x}_{\mathbf{1}}, \boldsymbol{x}_{\mathbf{2}} \in \mathbb{R}_{\text {max }}\right\}$ dengan operasi $\bigoplus$ dan $\otimes$ yang didefinisikan berikut:

$$
\begin{gathered}
x \oplus y=\left(x_{1}, x_{2}\right) \oplus\left(y_{1}, y_{2}\right)=\left(x_{1} \oplus y_{1}, x_{2} \oplus y_{2}\right) \\
x \otimes y=\left(x_{1}, x_{2}\right) \otimes\left(y_{1}, y_{2}\right) \\
=\left(\left(x_{1} \otimes y_{1}\right) \oplus\left(x_{2} \otimes y_{2}\right),\left(x_{1} \otimes y_{2}\right) \oplus\left(x_{2} \otimes y_{1}\right)\right) \\
\forall x=\left(x_{1}, x_{2}\right) ; y=\left(y_{1}, y_{2}\right) ; x_{1}, x_{2}, y_{1}, y_{2} \in \mathbb{R}_{\max }
\end{gathered}
$$

dengan elemen nolnya $(-\infty,-\infty)$ dan elemen satuannya $(\mathbf{0},-\infty)$.

Pada pasangan aljabar ini juga diperkenalkan operator-operator sebagai berikut :

1. Operator minus dinotasikan dengan $\ominus$

2. Operator absolut dinotasikan ||

3. Operator keseimbangan dinotasikan ${ }^{\circ}$

misal dimiliki $\boldsymbol{x}=\left(\boldsymbol{x}_{1}, \boldsymbol{x}_{2}\right)$, dijelaskan operator-operator tersebut sebagai berikut:

$$
\begin{gathered}
\ominus x=\left(x_{2}, x_{1}\right) \\
|x|=x_{1} \oplus x_{2} \\
x^{\circ}=x \ominus x
\end{gathered}
$$


Aljabar konvensional menjelaskan bahwa untuk setiap $x \in \mathbb{R}$ berlaku $x-x=0$. Sedangkan dalam pasangan aljabar ditunjukkan bahwa untuk setiap $x \in \mathbb{P}$ berlaku $x \ominus x=$ $x^{\circ} \neq(-\infty,-\infty)$. Oleh karena itu diperkenalkan relasi baru yaitu relasi $\nabla$.

Relasi $\nabla$ dibaca relasi keseimbangan didefinisikan sebagai

$$
x \nabla y \text { jika } x_{1} \oplus y_{2}=x_{2} \oplus y_{1}
$$

relasi $\nabla$ berkoresponden dengan $=$ dalam aljabar konvensional. Dengan relasi ini didapatkan bahwa untuk setiap $x \in \mathbb{P}$ berlaku $x \ominus x=x^{\circ} \nabla(-\infty,-\infty)$. Relasi $\nabla$ merupakan relasi refleksi, serta simetri, namun relasi ini tidak transitif. Hal ini dapat ditunjukkan misal dimiliki $(4,1) \nabla(4,4),(4,4) \nabla(2,3)$ tetapi tidak berlaku $(4,1) \nabla(2,3)$. Karena relasi $\nabla$ tidak transitif, maka tidak dapat dibentuk himpunan quotient dari relasi ini. Oleh karena itu, diperkenalkan lagi relasi baru berupa relasi $\mathcal{R}$ yang didefinisikan sebagai berikut:

$$
\begin{gathered}
x \mathcal{R} y \text { jika }\left\{\begin{array}{c}
x \nabla y, \text { jika } x_{1} \neq x_{2}, y_{1} \neq y_{2} \\
x=y \text { lainnya }
\end{array}\right. \\
\text { Untuk } x=\left(x_{1}, x_{2}\right) ; y=\left(y_{1}, y_{2}\right)
\end{gathered}
$$

Relasi $\mathcal{R}$ merupakan relasi ekuivalensi (bukti dapat dilihat dalam (Ulfa, 2015)). Sehingga dengan relasi $\mathcal{R}$ ini dapat dibentuk himpunan quotient berupa $\mathbb{S}=\mathbb{P} / \mathcal{R}=\left\{\left(x_{1}, x_{2}\right) \mid x_{1}, x_{2} \in\right.$ $\left.\mathbb{R}_{\text {max }}\right\}$. Himpunan $\mathbb{S}$ dilengkapi dengan operasi $\oplus$ dan $\otimes$ yang didefinisikan sebagai:

$$
\begin{gathered}
x \oplus y=\left(x_{1}, x_{2}\right) \oplus\left(y_{1}, y_{2}\right)=\left(x_{1} \oplus y_{1}, x_{2} \oplus y_{2}\right) \\
x \otimes y=\left(x_{1}, x_{2}\right) \otimes\left(y_{1}, y_{2}\right) \\
=\left(\left(x_{1} \otimes y_{1}\right) \oplus\left(x_{2} \otimes y_{2}\right),\left(x_{1} \otimes y_{2}\right) \oplus\left(x_{2} \otimes y_{1}\right)\right) \\
\forall x=\left(x_{1}, x_{2}\right) ; y=\left(y_{1}, y_{2}\right) ; x_{1}, x_{2}, y_{1}, y_{2} \in \mathbb{R}_{\max }
\end{gathered}
$$

karena himpunan $\mathbb{S}$ merupakan himpunan quotient, yaitu himpunan yang dilengkapi dengan relasi ekuivalensi. Maka terbentuk kelas-kelas dalam himpunan ini. Kelas-kelas ekuilensi yang terbentuk dijelaskan berikut ini:

1. Kelas $(t,-\infty)$ disebut dengan kelas max-positif dan disimbolkan:

$$
\mathbb{S}^{\oplus}=\left\{(t,-\infty) \mid t \in \mathbb{R}_{\max }\right\}
$$

2. Kelas $(-\infty, t)$ disebut dengan kelas max-negatif dan disimbolkan:

$$
\mathbb{S}^{\ominus}=\left\{(-\infty, t) \mid t \in \mathbb{R}_{\max }\right\}
$$

3. Kelas $(t, t)$ disebut dengan kelas seimbang (balance) dan disimbolkan:

$$
\mathbb{S}^{\circ}=\left\{(t, t) \mid t \in \mathbb{R}_{\max }\right\}
$$

4. Kelas $(\epsilon, \epsilon)=(-\infty,-\infty)$ disebut kelas nol

Dari himpunan $\mathbb{S}$ ini diperkenalkan dekomposisi dari $\mathbb{S}$ yaitu $\mathbb{S}=\mathbb{S}^{\oplus} \cup \mathbb{S}^{\ominus} \cup \mathbb{S}^{\circ}$ dan $\mathbb{S}^{\vee}=\mathbb{S}^{\oplus} \cup \mathbb{S}^{\ominus}$. Selain itu dapat dituliskan pula $\mathbb{S}^{\oplus} \cap \mathbb{S}^{\ominus} \cap \mathbb{S}^{\circ}=(\epsilon, \epsilon)$. Anggota-anggota dari $\mathbb{S}$, yaitu $x \in \mathbb{S}$ dituliskan sebagai berikut :

1. $x$, jika $x \in \mathbb{S}^{\oplus}$

2. $\ominus x$, jika $x \in \mathbb{S}^{\ominus}$

3. $\quad x^{\circ}$, jika $x \in \mathbb{S}^{\circ}$

4. $x=\epsilon$, jika $x=(\epsilon, \epsilon)$

Secara sederhana, korespondensi operator-operator dalam aljabar konvensional $(\mathbb{R})$ dengan aljabar max-plus tersimetri (S) disajikan dalam Tabel 1. 
Tabel 1. Korespondensi $\mathbb{R}$ dengan $\mathbb{S}$

\begin{tabular}{ccc}
\hline No. & $\mathbb{R}$ & $\mathbb{S}$ \\
\hline 1 & + & $\oplus$ \\
2 & - & $\ominus$ \\
3 & $\times$ & $\bigotimes$ \\
4 & $=$ & $\nabla$ \\
5 & 0 & $\epsilon$ \\
6 & 1 & 0 \\
7 & $\mathbb{R}^{+}$ & $\mathbb{S}^{\oplus}$ \\
8 & $\mathbb{R}^{-}$ & $\mathbb{S}^{\ominus}$ \\
\hline
\end{tabular}

Dengan terbentuknya aljabar max-plus tersimetri ini, dekomposisi QR dapat dilakukan dalam aljabar max-plus. Dekomposisi ini diawali dengan memetakan himpunan aljabar maxplus tersimetri $(\mathbb{S})$ kedalam himpunan bilangan real $(\mathbb{R})$ berupa fungsi eksponensial. Penjelasan tentang pemetaan ini dijelaskan dalam (Schutter \& Moor, 2002) atau (Ulfa, 2015). Kemudian Bart De Schutter dan Bart De Moor menjelaskan bahwa dekomposisi QR dalam aljabar maxplus tersimetri yaitu dekomposisi matriks $A \in \mathbb{S}^{m \times n}$ menjadi perkalian matriks ortogonal $Q \in$ $\left(\mathbb{S}^{\vee}\right)^{m \times m}$ dengan matriks segitiga atas $R \in\left(\mathbb{S}^{\vee}\right)^{m \times n}$, atau dapat dituliskan sebagai:

$$
\boldsymbol{A}=\boldsymbol{Q} \otimes \boldsymbol{R}
$$

Dalam pembentukan himpunan $\mathbb{S}$ didapatkan himpunan $\mathbb{S}^{\circ}$. Himpunan ini merupakan himpunan baru. Dalam aljabar konvensional, biasa dikenal himpunan bilangan positif $(+)$, himpunan bilangan negatif (-), atau himpunan bilangan nol (0). Himpunan baru tersebut dirasa menarik oleh peneliti, sehingga penelitian ini akan membahas tentang dekomposisi QR dalam aljabar max-plus tersimetri dengan beberapa entri matriks awal yang akan di dekomposisi merupakan bilangan dalam himpunan $\mathbb{S}^{\circ}$.

\section{METODE}

Jenis penelitian yang digunakan dalam penelitian ini adalah jenis penelitian studi literatur tau penelitian teori. Penelitian studi literatur atau penelitian teori adalah serangkaian kegiatan yang berkenaan dengan metode pengumpulan data pustaka, membaca dan mencatat serta mengolah bahan penelitian (Zed, 2008). Pendekatan penelitian yang digunakan merupakan pendekatan kualitatif. Menurut Sugiyono dalam (Depdiknas, 2008), pendekatan kualitatif adalah pendekatan penelitian yang digunakan untuk meneliti pada kondisi objek alamiah dimana peneliti merupakan instrumen kunci (Sugiyono, 2018).

Penelitian yang dilakukan dengan cara mengumpulkan data berupa teori tentang dekomposisi QR, teori tentang aljabar max-plus, teori tentang aljabar max-plus tersimetri, dan teori tentang dekomposisi QR dalam aljabar max-plus tersimetri. Setelah data tersebut terkumpul, selanjutnya data tersebut dipelajari dan dianalisa. Analisa yang ada dituangkan dalam beberapa hasil percobaan perhitungan dekomposisi QR dalam aljabar max-plus tersimetri. Dalam memperbanyak percobaan perhitungan, peneliti menggunakan bantuan aplikasi Matlab 2013a dan Mapel 2017 sebagai alat bantu hitung serta alat bantu cek hasil perhitungan yang ada.

Setelah hasil percobaan dirasa cukup, maka peneliti melihat dan mengelompokkan pola sesuai dengan ciri khas masing-masing percobaan. Pola tersebut kemudian disajikan dalam 
teori yang akan ditunujukkan dalam bagian hasil. Kemudian teori tersebut dibuktikan sebagai pertanggung jawaban kebenaran sebuah teori.

\section{HASIL DAN PEMBAHASAN}

Dengan data berupa teori yang ada, dan hasil percobaan yang dilakukan peneliti mendapat pola untuk setiap $x \in \mathbb{S}^{\circ}$ berarti sesuai dalam pernyataan persamaan (18) $x=x^{\circ}$, berlaku sebagai berikut.

$$
\begin{gathered}
x^{\circ} \oplus x^{\circ}=(x, x) \oplus(x, x)=(x \oplus x, x \oplus x)=(x, x)=x^{\circ} \\
x^{\circ} \oplus x=(x, x) \oplus(x,-\infty)=\left(x \oplus x, x \oplus-\infty=(x, x)=x^{\circ}\right. \\
x^{\circ} \oplus(\bigoplus x)=(x, x) \oplus(-\infty, x)=(x \oplus-\infty, x \oplus x)=(x, x)=x^{\circ} \\
x^{\circ} \oplus \epsilon=(x, x) \oplus(-\infty,-\infty)=(x \oplus-\infty, x \oplus-\infty)=(x, x)=x^{\circ}
\end{gathered}
$$

Hasil persamaan pada (21), (22), (23), (24) didapatkan teori bahwa misalkan dimiliki matriks $A \in \mathbb{S}^{m \times n}$ dengan beberapa entri elemen balance, kemudian dimiliki $B \in\left(\mathbb{S}^{\vee}\right)^{m \times n}$ dengan ketentuan:

$$
b_{i, j}=\left\{\begin{array}{c}
a_{i, j}, j i k a a_{i, j} \in \mathbb{S}^{\vee} \\
\left|a_{i, j}\right| \text { atau } \ominus\left|a_{i, j}\right| \text { atau } a_{i, j}, \text { jika } a_{i, j} \in \mathbb{S}^{\circ}
\end{array}\right.
$$

kemudian dekomposisi QR dari $A \nabla Q \otimes R$ maka dekomposisi QR dari $A \oplus B \nabla Q \otimes R$ Dalam teori di atas, misal:

$$
A=\left[\begin{array}{cccc}
a_{1,1} & a_{1,2} & \ldots & a_{1, n} \\
a_{2,1} & a_{2,2} & \ldots & a_{2, n} \\
\vdots & \vdots & \ddots & \vdots \\
a_{m, 1} & a_{m, 2} & \ldots & a_{m, n}
\end{array}\right] \quad B=\left[\begin{array}{cccc}
b_{1,1} & b_{1,2} & \ldots & b_{1, n} \\
b_{2,1} & b_{2,2} & \ldots & b_{2, n} \\
\vdots & \vdots & \ddots & \vdots \\
b_{m, 1} & b_{m, 2} & \ldots & b_{m, n}
\end{array}\right]
$$

dengan ketentuan dalam teori yang ada, dimiliki 6 kemungkinan dalam operasi $A \oplus B$ berikut:

1. $a_{i, j} \oplus b_{i, j}=a_{i, j} \oplus a_{i, j}=a_{i, j \text { untuk }} a_{i, j} \in \mathbb{S}^{\oplus}$

2. $a_{i, j} \oplus b_{i, j}=a_{i, j} \oplus a_{i, j}=a_{i, j \text { untuk }} a_{i, j} \in \mathbb{S}^{\ominus}$

3. $a_{i, j} \oplus b_{i, j}=a_{i, j} \oplus\left|a_{i, j}\right|=a_{i, j \text { untuk }} a_{i, j} \in \mathbb{S}^{\circ}$

4. $a_{i, j} \oplus b_{i, j}=a_{i, j} \oplus\left(\ominus\left|a_{i, j}\right|\right)=a_{i, j}$ untuk $a_{i, j} \in \mathbb{S}^{\circ}$

5. $a_{i, j} \oplus b_{i, j}=a_{i, j} \oplus a_{i, j}=a_{i, j \text { untuk }} a_{i, j} \in \mathbb{S}^{\circ}$

6. $a_{i, j} \oplus b_{i, j}=a_{i, j} \oplus a_{i, j}=a_{i, j \text { untuk }} a_{i, j}=(\epsilon, \epsilon)$

Sehingga jelas bahwa $A=A \oplus B$ untuk ketentuan yang telah disebutkan. Sehingga jelas bahwa jika dekomposisi QR dari $A \nabla \mathrm{Q} \otimes \mathrm{R}$ maka dekomposisi QR $A \oplus B \nabla Q \otimes R$.

\section{SIMPULAN}

Peneliti menyimpulkan bahwa karakteristik solusi dekomposisi QR dalam ajabar maxplus tersimetri didapatkan bahwa misal dimiliki matriks $A \in \mathbb{S}^{m \times n}$ dengan beberapa entri elemen balance, kemudian dimiliki $B \in\left(\mathbb{S}^{\vee}\right)^{m \times n}$ dengan ketentuan

$$
b_{i, j}=\left\{\begin{array}{c}
a_{i, j}, j \text { ika } a_{i, j} \in \mathbb{S}^{\vee} \\
\left|a_{i, j}\right| \text { atau } \ominus\left|a_{i, j}\right| \text { atau } a_{i, j}, j i k a a_{i, j} \in \mathbb{S}^{\circ}
\end{array}\right.
$$


kemudian dekomposisi QR dari $A \nabla Q \otimes R$ maka dekomposisi QR dari $A \oplus B \nabla Q \otimes R$.

Hasil karakteristik solusi dekomposisi QR dalam aljabar max-plus tersimetri dalam penelitian ini masih dalam ruang lingkup yang kecil. Penelitian selanjutnya dapat dilakukan dalam lingkup yang lebih besar. Tidak hanya dalam entri kelas balance-nya, tetapi dalam jenisjenis matriks $A$ yang akan di dekomposisi.

\section{DAFTAR PUSTAKA}

Anton, H. (1987). Aljabar Linear Elementer. Edisi 5. Jakarta: Erlangga.

Bacelli, F. d. (2001). Synchronization and Linearity An Algebra. New York: John Wiley and Sons.

Depdiknas. (2008). Pendekatan, Jenis, dan Metode Penelitian Pendidikan. Jakarta: Direktorat Tenaga Kependidikan, Direktorat Jenderal Peningkatan Mutu Pendidik dan Tenaga Kependidikan,Departemen Pendidikan Nasional.

Golub, G. H., \& Loan, C. F. (1996). Matrix Computation, Third Edition. London: The Johns Hopkins Press Ltd.

Ruminta. (2014). Matriks (Persamaan Linier dan Pemrograman. Bandung: Rekayasa Sains.

Schutter, B. D., \& Moor, B. D. (2002). The QR Decomposition and the Singular Value Decomposition in the Symetrized Max-Plus. SIAM, 44(3), 417-454.

Sugiyono. (2018). Metode Penelitian Kuantitatif, Kualitatif, dan R\&D. Bandung: Alfabeta.

Ulfa, K. (2015). Dekomposisi Nilai Singular dalam Aljabar Max-Plus Tersimetri. Tesis. Yogyakarta: Program Studi S2 Matematika Universitas Gadjah Mada.

Zed, M. (2008). Metode Penelitian Kepustakaan. Jakarta: Yayasan Obor Indonesia. 